\title{
Determinants and Effects of Diagnostic and Interactive Use of Budget in Iranian Companies
}

\author{
Farzane Jalali Ali Abadi, Alemeh Yazdanian, Elham Jamali* \\ Department of Management, University of Tehran, Tehran, Iran \\ Email address: \\ fajalali@ut.ac.ir (F. J. Ali Abadi), almyazdanian@ut.ac.ir (A. Yazdanian), Jamali.accounting@gmail.com (E. Jamali) \\ ${ }^{*}$ Corresponding author
}

\section{To cite this article:}

Farzane Jalali Ali Abadi, Alemeh Yazdanian, Elham Jamali. Determinants and Effects of Diagnostic and Interactive Use of Budget in Iranian Companies. International Journal of Business and Economics Research. Vol. 5, No. 3, 2016, pp. 46-54. doi: 10.11648/j.ijber.20160503.13

Received: November 17, 2015; Accepted: December 16, 2015; Published: May 11, 2016

\begin{abstract}
Regarding the vital role of budget as a major feature of management control systems (MACS) in various fields like formulation of strategy, development of dynamic capabilities, competitive advantage; and additionally, due to the low volume of empirical research in this area, this paper investigates the application of budget in different Iranian companies. For this purpose, we first considered the diagnostic and interactive approaches toward MACS which are introduced by Simon (1990). We also focused on the model of Hofmann, Wald \& Gleich (2012) to develop our research model and hypothesis. Finally, based on Hofmann, et al. (2012) study, we consider variables that may influence budget use such as environmental, organizational and individual factors. Findings show that leadership behavior, user attitude, competitive intensity and interactive use are determinants in diagnostic use. Besides, factors such as market dynamism, centralization, culture of trust, user attitude and leadership behavior influence the level of interactive use of budgets. Further, our research shows that both kinds of budget usage influence formulation and implementation of the strategy and diagnostic use of budgets has a significant and positive impact on financial performance.
\end{abstract}

Keywords: Diagnostic Use, Interactive Use, Budget, Management Control System

\section{Introduction}

In a highly dynamic competitive environment, management accounting control systems (MACS) are gaining significance. They are used for planning, decision- making, ex-post evaluation and incentive systems (Hofmann, Wald \& Gleich, 2012). According to Antony (1965) definition, "management control system is a processing that management ensures whether resources are used effectively and efficiently in achieving the organization goals." MACS are systems which collect the information in order to evaluate the performance of organization resources and ultimately affect the organizational behavior for realizing organization strategy. Armesh, Salarzehi \& Kord (2010) believe that MACS include devices and systems used to ensure that employee decisions are aligned with organization strategy and goals. One of the traditional management control systems is budget. Budgets are primarily used as synonyms for financial plans. They provide a basis to coordinate and to control the organizational activities, and to evaluate the performance of the executing individuals and the corresponding subunits. Zimmermann (2006: 260) defines budgets as "management's formal quantification of the operations of an organization for a future period". This underlines that budgets comprise not only the quantities of economic resources to be allocated and used but also the goals to be achieved (Hofmann, et al. 2012).

Simons (1990) states that almost all organizations have similar management control systems (as budget), but how the control systems are used by senior management organizations is very different. He points out that all control systems can be used in two ways: diagnostic and interactive (Chong \& Mahama, 2013). The diagnostic use refers to the traditional role of budget in providing feedback and monitoring the achievement of pre-established goals. This process comprises the review of critical performance variables to monitor and to coordinate the implementation of intended strategies (Hofmann, et al. 2012). According to the Simon (2000) study, diagnostic use of budget happens when senior management 
wants to use controlling systems in order to actively involve subordinates in decision making process. Simon (1994) discusses that diagnostic use can change to interactive use of budget by continued participation of senior management. This type of participation by senior management provides opportunities which they can interact with their subordinates and exchange the information (Chong \& Mahama, 2013).

The different studies about the determinants and consequences of the use of MACS demonstrate that they are influenced by a series of factors and using of them influences important variables likes organizational capabilities, strategy, and performance. One of these studies refers to Hofmann, et al. (2012) research. Accordingly, given the lack of empirical research on Simon's typology and the centrality of budgets as the major feature of MACS, this paper seeks to empirically examine the determinants and consequences of the diagnostic and interactive use of budgets. Budgets are primarily used as synonyms for financial plans. The paper is organized as follows: After reviewing of the literature study and describing and explaining of the assumptions, research methodology will be discussed. Then, the results of statistical analysis, discussion and conclusions will be presented in detail.

\section{Literature Review}

The broad literature on MACSs (Simons, 1991, 1994, 1995; Langfield-Smith 1997; Haas and Kleingeld, 1999; and Kaplan and Norton, 2001, among others) distinguishes the use of MACSs in diagnostic and interactive use. According to Green and Welsh(1988) MACSs are described as information feedback systems, where goals are set in advance, outcomes are compared with preset objectives, and important variances are given to management teams for amendments, adjustments and follow-up. Since this type of systems is considered as the primary tool for managementby-exception, the literatures characterize them as diagnostic control systems (Theriou, Maditinos and Sevic, 2009).

On the other hand, Brownell (1999) argues that budget has a potential to be used interactively; because the budget is discussed between different parts of organization. When the budget is used interactively, different members of organization are involved in decision-making and planning process (Chong \& Mahama, 2013).Simons (1991) mentions that MACSs are not always used to manage by exception. In many cases, top management uses MACSs for day-to-day issues to support organizational decision making. Thus, from Simon's point of view MACSs can be referred to as an interactive operation when top management teams use them personally and regularly to involve themselves in the decisions of subordinates (Theriou, Maditinos \& Sevic, 2009).

Even though different research has been done pertaining the significant concept of MACS, the concepts of diagnostic and interactive control do still receive limited attention. Widener (2007) examined the relation between strategic risks, uncertainty, and control systems. Abernethy and Brownell (1999) looked at the style of budget use and strategic change. Abernethy et al. (2010) investigated the role of leadership for the choice of MACS. Empirically they found leadership style to be a predictor for the use of MACS. Bisbe and Otley (2004) analyzed whether the interactive use of MACS positively affects product innovation (2004). Henri (2006) did not focus at determinants of MACS use but considered the outcomes in terms of strategic capabilities. His results indicate that the use of MACS contributes to organizational performance and that a balance between the diagnostic and the interactive use of MACS creates a dynamic tension which positively affects organizational capabilities. In a similar vein, Mundy (2010) conducted a case study in a multinational financial service firm to analyze how organizations balance the different uses of MACS. She also found that a balanced use of MACS creates a dynamic tension which is supposed to positively affect firm performance (Hofmann, et al. 2012).

Chong \& Mahama (2013) by reference to Simon (1994, 1995, and 2000) studies reviewed the impact of diagnostic and interactive use of budget on team work efficiency in biotechnology companies. The results show that interactive use of budget has direct effect on team work.

Hofmann, et al. (2012) studied the determinants and effects of diagnostic use of control system. They used budget as a MACs and by use of different companies they analyze the environmental uncertainty, organizational and individual factors and their effects on budget and also consequences of budget use including formulation of new strategies, current strategy formulation and financial performance. They concluded as follows:

1. Environmental uncertainty factors including competitive intensity and environmental dynamism just have influenced interactive use of budget. In a way that Competitive intensity has a positive effect and environment dynamism has a negative impact.

2. There is no significant relationship between centralization, as organizational factor, and diagnostic use of budget, however; it has a negative relationship with interactive use. On the other hand, there is no meaningful relationship between trust culture and interactive use of budget while, this relation is positive and significant between trust culture and diagnostic budgeting.

3. Users' attitude as an individual factor has a positive and significant effect on diagnostic and interactive use of budget. Of other individual factor, leadership behavior, post no significant relationship with diagnostic budgeting. Interactive budgeting, on the other hand, requires a high level of leadership characteristic among the organization members. Consensus, as the last individual factor, forms a positive, meaningful relationship with diagnostic usage of budget.

4. Diagnostic and interactive uses of budgeting have also internal and supplementary relationship between each other. This means that interactive use, affects diagnostic one positively and significantly.

5. Either of interactive and diagnostic use of budgeting contributes to development and execution of new 
strategies. Moreover, interactive use of budgeting has a negative but diagnostic budgeting has a positive effect on financial performance.

Unfortunately, there is no record of a prior research into the different types of MACS application in Iran including the influential factors on budgets and their consequences. Thus, due to this lack of previous research and the significance of identifying the determinant factors in improving of organization functionality, in this paper, it has been tried to recognize these factors by questioning the personnel who directly dealwith budgeting. This will help develop concrete base for further research in this field.

\section{Hypothesis Development}

Following the research of Hofmann, et al. (2012), different factors can influence the use of budget (diagnostic and interactive), such as: (1) environmental uncertainty as contingency factors (including market dynamism, competitive intensity); (2) organizational factor (including centralization and culture of trust); (3) individual factors (including user attitudes, leadership behavior, and consensus). Also by reference to Hofmann, et al. (2012), the consequences of budget use on strategy implementation and financial performance is notable. As a result, in current research, efforts are being made to answer the following questions according to budget implementation in various Iranian organizations.

How internal and external factors affect diagnostic and interactive use of budget?

- Does diagnostic and interactive use of budget affect new strategies development and predefined strategy implementation?

- Does diagnostic and interactive use of budget affect organization performance?

\subsection{Environmental Uncertainty as Contingency Factors}

Hofmann, et al. (2012) considered market dynamism and competitive intensity as important factors that affect environmental uncertainty.

They defined market dynamism as strategic uncertainty and they stated that in order to manage such uncertainty, this is necessary to select diagnostic and interactive strategies of management accounting control systems.

Empirical studies support the hypothesis that there is a positive relationship between market dynamism and the use of management accounting control systems. Mia (1993) investigated the relationship between the environmental uncertainty, use of management accounting control systems (MACS) information and job performance. His findings suggest that with a higher uncertainty the managerial use of MACS information is increasing. Mia states that such information enlarges the managers' capacity for learning about emerging opportunities and problems and enables the managers to initiate the appropriate actions in response. Gordon and Narayanan (1984) examined the relationships between environmental uncertainty, organizational structure and the use of information systems. They found a positive relationship between perceived environmental uncertainty and externally oriented information as well as non-financial oriented information. Chenhall and Morris (1986) considered the relationships between the environmental uncertainty and budgetary systems. Their results indicate that managers facing uncertainty require a broad scope of information to scan the environment for emerging opportunities and threats and to trigger revised action plans. Bisbe and Otley (2004) found that the interactive use of budgets reduces the uncertainty associated with product innovation and Davila (2000) revealed a positive relationship to market and technological uncertainties. Widener (2007) showed that strategic risks and uncertainties lead to higher use of information requirements and diagnostic and interactive control systems. Hofmann, et al (2012) also concluded that dynamism of environment just has a negative impact on interactive use of budget.

In order to investigate the relationship between the market dynamism and the use of budget, two following hypotheses can be formulated:

$\mathrm{H}_{\mathrm{a}}$ : Market dynamism is positively related to the diagnostic use of budgets.

H1b: Market dynamism is positively related to the interactive use of budgets.

On the other hand, Hofmann, et al. (2012) point out that competitive intensity, as another important factor in the field of environmental uncertainty, allows customers to choose from various options. This problem causes organizations to develop their knowledge in the changeable tendency area of customers. Early empirical research demonstrated that increasing competitive intensity is positively related to a diagnostic and interactive use of budget (Libby and Waterhouse (1996), Khandwalla (1972), Otley (1978), Brignall (1997), Chong et al (2005); which Hofmann et al. (2012) also concluded the same in the interactive use of budget field.

In order to investigate the relationship between competitive intensity and the use of budgeting, two following hypotheses can be formulated:

$\mathrm{H} 2 \mathrm{a}$ : Competitive intensity is positively related to the diagnostic use of budgets.

$\mathrm{H} 2 \mathrm{~b}$ : Competitive intensity is positively related to the interactive use of budgets.

\subsection{Organizational Factors}

In the Hofmann, et al. (2012) research, centralization and trust culture are considered as organization factors. Centralization describes the degree to which the decisionmaking authority is concentrated at the top management level. Frederickson (1986) and Simons (2005) showed that in centralized structures, top management utilizes MACS not only to control the organizational activities but also to learn about them and, use them in a diagnostic and in an interactive way. In such an environment, budget plays an important role in communication between managers and subordinates. When the decision making authority is centralized, the use of 
MACs supports the vertical information flow in an organization which, in turn, decreases the uncertainty of top management throughout the decision processes and so a higher centralization may lead to an increase in the use of budgets (Hofmann, et al. 2012). Also the results of Hofmann, et al. (2012) study suggest that there is no significant relationship between centralization and diagnostic use of budget, while centralization has a negative effect on interactive use of budget.

So the relationship between centralization and how to use of budget can be formulated as following:

$\mathrm{H} 3 \mathrm{a}$ : Centralization is positively related to the diagnostic use of budgets.

$\mathrm{H} 3 \mathrm{~b}$ : Centralization is positively related to the interactive use of budgets.

Trust culture is considered as an aspect of organizational factors. Simons (2005) defines the role of trust as diagnostic and interactive control. The correct functioning of the two levels of control may only be ensured if the 'right people' are involved. A high level of trust is not only associated with greater communication and improved joint problem-solving but also results in uncovering new solutions and therefore may promote the interactive use of budgets. The diagnostic use of budgets relies on management by exception where, in order to save scarce management attention, managers become only involved in the case of major budget deviations (Hofmann, et al. 2012). They result that trust culture doesn't have a positive relationship with interactive use of budget; while there is a positive relationship between trust and diagnostic use of budgets. Therefore there is a positive relationship between trust and the use of budgets:

$\mathrm{H} 4 \mathrm{a}$ : Culture of trust is positively related to the diagnostic use of budgets.

$\mathrm{H} 4 \mathrm{~b}$ : Culture of trust is positively related to the interactive use of budgets.

\subsection{Individual Factors}

Several studies on the use of MACs have analyzed the influence of the user's attitudes at the individual level. User attitudes include the personality of the user, i.e. specific attitudes and other personal attributes, such as age, education, and years of experience on the job. The management's attitude towards the information available may influence the application of MACs within the company (Hofmann, et al. 2012). They concluded that users attitudes as an aspect of individual factor has a significant effect on diagnostic and interactive use of budget.

Therefore it is assumed that user's attitude has a positive effect on both, the diagnostic and the interactive use of budgets:

H5a: An affirmative user attitude towards budgeting has a positive effect on the diagnostic use of budgets.

$\mathrm{H} 5 \mathrm{~b}$ : An affirmative user attitude towards budgeting has a positive effect on the interactive use of budgets.

Following Simons (1987a, 1991, and 2005) and Hofmann, et al. (2012) study, we assume that top managers' leadership styles influence the method of control systems use. Hofmann, et al. (2012) showed that leadership behavior doesn't have any relationship with diagnostic use of budget while interactive use of budget needs high degree of leadership behavior between organization members. Abernethy et al. (2010) examined the relationship between leadership style and the interactive use of planning. Their findings suggested that the initiating structure leadership style is positively related to the interactive use and control systems. The interactive use of budgets requires high degrees of both task and employee- oriented leadership behaviors. Managers need to be task-oriented since they play active roles in directing the subordinates' activities through planning, communicating information and scheduling. With a focus on management roles and budget behaviors in their study they showed that the budget will appear in the role of defense. They concluded that a manager who is responsible for resource allocation and environmental monitoring activities uses the budget to motivate subordinates (Hofmann, et al. 2012). So the relationship between leadership behavior and diagnostic \& interactive use of budget is formulated as below:

H6a: Leadership behavior is positively related to the diagnostic use of budgets.

H6b: Leadership behavior is positively related to the interactive use of budgets.

Consensus is the general agreement among individual members of a group and the degree to which they share a common view or judgment regarding a decision. The diagnostic use of budgets requires organizations to define ultimate goals which are well understood by all members of the organization. The number of goals should not exceed a certain limit so that their manageability is ensured and a general consensus on these goals should exist. Diagnostic control is likely to fail in the case of confusing goals (Simons 2005). If budgets are to be used diagnostically, members of the organization should have the same understanding and agree upon the interpretation of the critical performance variables. Furthermore, consensus highly contributes to saving scarce management attention as it reduces the time spent on conflict resolution. Therefore Consensus should be positively related to the diagnostic use of budgets.

When budgets are to be used interactively, organizational attention is focused and dialogue enforced throughout the organization. In that regard, consensus must not only exist among top management levels but needs to be achieved throughout the entire organization. The interactive use of budgets is assumed to be positively related to organizational learning and research showed that consensus is a prerequisite for organizational learning. Therefore, consensus should be positively related to the interactive use of budgets (Hofmann, et al. 2012). This is despite the fact that Hofmann, et al. just showed the positive effect between consensus and diagnostic use of budget.

Therefore the hypothesis will be formulated as below:

$\mathrm{H} 7 \mathrm{a}$ : Consensus is positively related to the diagnostic use of budgets.

$\mathrm{H} 7 \mathrm{~b}$ : Consensus is positively related to the interactive use of budgets. 


\subsection{Relationship Between Interactive and Diagnostic Budget Use}

Several authors accentuated the interdependence of MACs use features (Milgromand Roberts 1995; Otley 1999; Abernethy et al. 2004; Simons 2000). However, it remains unclear from an empirical perspective whether such interdependencies do actually complement each other or have substitution character; In this case Simons (1995) states that as soon as a strategy emerges due to interactive control, the diagnostic control has to be adapted by establishing appropriate critical performance variables in order to keep track of the newly developed strategy. The positive relationship between interactive and diagnostic use of budgets is also demonstrated in a case study (Hofmann, et al. 2012). Also Hofmann, et al. concluded a positive relationship between the diagnostic and the interactive use of budgets.

Hypothesis will be formulated as below:

$\mathrm{H} 8$ : The interactive use of budgets is positively related to the diagnostic use of budgets.

\subsection{Consequences of Budget Use}

As it is mentioned earlier, the second step in this research is reviewing the consequences of diagnostic and interactive use of budget. Also it is mentioned that by reference to Hofmann, et al. (2012) research, we can review the consequences of budget use on Strategy formulation and financial performance. Therefore we will formulate hypothesis in next parts:

\subsection{Formulation and Implementation of Strategy}

There is low empirical works that investigate the coherence between the use of budgets and formulation and implementation of strategy. One of this works is Abernethy and Brownell (1999) study. They revealed that when firm performance is high and budgets are used interactively then the level of strategic change increase. In contrast, the diagnostic use of budgets is more appropriate in a situation of low strategic change. Hofmann, et al (2012) also addressed this topic in their research. They concluded that both types of budget uses help new strategy formulation and implementation. The classical strategy process is often conceptualized as the rational progression from strategy formulation to strategy implementation. Therefore related hypothesis can be formulated as below:

H9a: Diagnostic use of budgets is positively related to intended strategy implementation.

$\mathrm{H} 9 \mathrm{~b}$ : Interactive use of budgets is positively related to intended strategy implementation.

H10a: diagnostic use of budgets is positively related to emergent strategy formulation.

H10b: Interactive use of budgets is positively related to emergent strategy formulation.

\subsection{Financial Performance}

Following the research of Hofmann, et al. (2012), in this study we review the relationship between various uses of budget and its effects on organization performance. Hofmann, et al. (2012) implies that there is a critical discussion on how far organizational performance may actually be influenced by individual behavior. Also by reference to Hambrick and Mason (1984) research, they emphasis that this assumption is grounded in the literature which integrates theories of organizational behavior. The proponents of this approach postulate that organizational outcomes such as strategy formulation and implementation as well as firm performance actually reflect the values and cognitive bases, as well as the quality of the decisions of organizational individuals. Hofmann, et al (2012) concluded that interactive \& diagnostic use of budget respectively has a negative and positive effect on financial performance.

Therefore the effect of budget consequences on financial performance can be formulated as below:

H11a: Diagnostic use of budgets is positively related to financial performance.

$\mathrm{H} 11 \mathrm{~b}$ : Interactive use of budgets is positively related to financial performance.

\section{Research Method}

\subsection{Data Collection}

We used Hofmann, et al. (2012) questionnaire to collect needed data for testing the hypothesis. It should be noted that the questionnaire, in addition to the general questions about respondents' personal information, has 12 other sections that 2 parts of them are about diagnostic and interactive use of budget, 7 parts for effective drivers on budget and 3parts about the consequences of diagnostic and interactive use of budget. By reference to Hofmann, et al (2012) research, it is clear that each parts of the questionnaire is designed to take advantage of previous research. The method of measuring variables is presented in the following table by reference to each part of questionnaire.

Table 1. Used resources to design different parts of the questionnaire by reference to Hofmann, Wald \& Gleich (2012).

\begin{tabular}{llll}
\hline Row & Variable & Symbol & Reference for Measurement \\
\hline 1 & Diagnostic use of budget & DU & Cent(2003) \\
2 & Interactive use of budget & IU & \\
3 & market dynamism & MD & Homburg et al(1999) \\
4 & competitive intensity & CI & Jaworski and Kohli (1993) \\
5 & centralization & CE & \\
6 & trust culture & CT & Reynolds (1986) \\
7 & attitude users & UA & Elizur and Guttman (1976) \\
8 & leadership behaviour & LB & Marginson and Ogden (2005) \\
9 & consensus & CO & Willauer (2004) \\
10 & Strategy implementation & SF & Mintzberg and Waters (1985); \\
11 & Strategy formulation & SI & Steiners (2005) \\
12 & Financial performance & FP & Powell (1996) \\
\hline
\end{tabular}


The content validity of the questionnaire is determined by professional experts and professors. Therefore, in order to ensure the content validity of the questionnaire, the opinions of several experts in this field were examined. To check the reliability of questionnaire, Cronbach alpha was calculated for each sections of the questionnaire as follow.

Table 2. Cronbach alpha amount for each part of questionnaire.

\begin{tabular}{lllllllllllll}
\hline Variable name & DU & IU & MD & CI & CE & CT & UA & LB & CO & SF & SI & FP \\
\hline Cronbach alpha & 0.67 & 0.72 & 0.54 & 0.71 & 0.61 & 0.5 & 0.52 & 0.51 & 0.85 & 0.78 & 0.91 & 0.83 \\
\hline
\end{tabular}

It is clear that how much Cronbach alpha scale near to 1 , internal correlation of question will increase and then questions will be more homogeneous. Cronbach (1951) has suggested $50 \%$ validity coefficient as average and $70 \%$ as high. Finally the results show that the questionnaire has an acceptable validity.

\subsection{Sample Selection}

In order to assess the views and opinions of Iranian employees indifferent companies, all public and private companies which benefit the budget as a management control system was considered as statistical population.

In order to collect the data, we distributed an online questionnaire to 478 employees of different companies. Finally, 100 questionnaires had been returned which 10 questionnaire were removed because of unrelated responses and 90 questionnaires (response rate $=18.8 \%$ ) were reviewed.

\subsection{Data Analysis}

First, in order to determine the normal distribution of data, we use the Kolmogorov-Smirnov test. The results of this test show that with confidence level of $99 \%$, data is distributed normally. On the other hand, in order to provide a model for the relationship between several independent and dependent variables at the same time, structural equation modeling should be used (Hofmann, et al. 2012). The techniques of solving structural equation modeling divide into two parts including covariance-based SEM and SEM based on partial least squares. Because of the relatively small sample size, partial least squares techniques (PLS) are used for testing the assumptions in this study. Partial least squares technique is a multivariate analysis technique for testing structural equation model and general model for estimating path model involving latent constructs which are indirectly measured with multiple indicators. The technique can be used for small samples, and those who do not have any assumptions about population or measurement scale (Hofmann, et al. 2012).

\section{Findings}

\subsection{Descriptive Statistics}

As it mentioned, the first part of the questionnaire is related to public specifications of respondents. Received responses indicate that 67 of the respondents were male and 23 of them were female. Also the abundance of jobs, type of organization and work experience are presented as below charts.

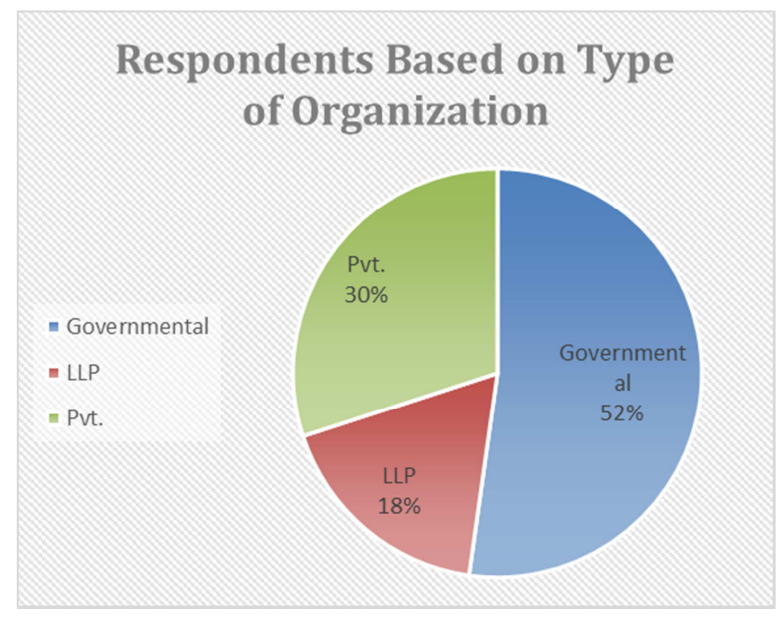

Figure 1. Descriptive Statistic of type of organization.

RESPONDENTS BASED ON ORGANISATIONAL RANK

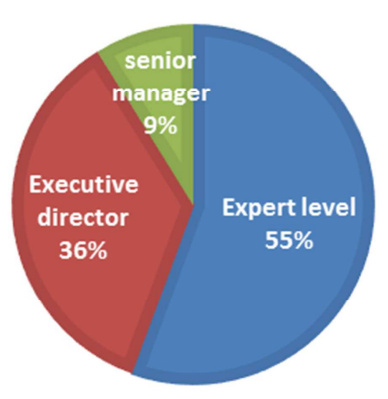

Expert level Executive director a senior manager

Figure 2. Descriptive Statistic of jobs abundance.

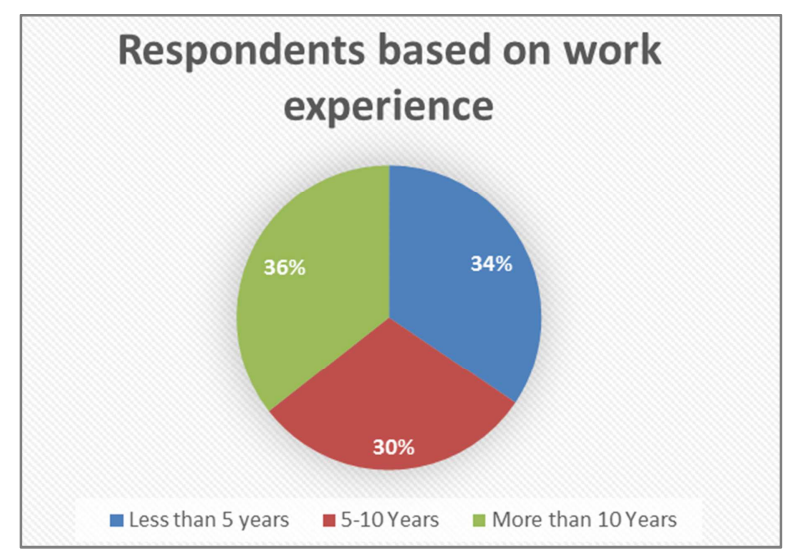

Figure 3. Descriptive Statistic of work experience. 


\subsection{Inferential Statistics}

As it mentioned in the previous section, the technique of partial east squares and PLS software are used to test the hypothesis of the study. This software can estimate T-value amounts by Boot strap and Jackknife. In the confidence level of $95 \%$ the numbers which are bigger 1.96 and smaller -1.96 are significant and the assumption will be accepted otherwise it will be rejected and in the confidence level of $90 \%$ numbers will change to 1.65 and -1.65 . In following, the results of Boot strap method are presented for the determinants of interactive and diagnostic use of budget.

\section{Determinants of the Interactive and Diagnostic Use of Budgets}

Table (3) \& (4) show the expected effects of determinants of the diagnostic and interactive use of budget, the path coefficients, and the t-statistics that computed by boot strap method. As it is shown in table 3 and by comparison of Tstatistic with 1.96 and -1.96 numbers for confidence level $95 \%$ and 1.65 and -1.65 for confidence level $90 \%$, it can be concluded that competitive intensity, trust culture, leadership behavior and interactive use of budget had a significant relationship with diagnostic use of budget at $90 \%$ confidence level, so $\mathrm{H} 2_{\mathrm{a}}, \mathrm{H} 4_{\mathrm{a}}, \mathrm{H} 6_{\mathrm{a}}, \mathrm{H} 8_{\mathrm{a}}$ are approved. Also the results show that there is a significant relationship between user's attitudes and diagnostic use of budget and then $\mathrm{H} 5_{\mathrm{a}}$ is accepted. Also Coefficient of Determination in the last line show that effective determinants on interactive use of budget explain $60 \%$ changes of this kind of budget use.

Table 3. Determinants of the diagnostic use of budgets.

\begin{tabular}{llll}
\hline $\begin{array}{l}\text { Effective determinants of the } \\
\text { diagnostic use of budgets }\end{array}$ & $\begin{array}{l}\text { Expected } \\
\text { effect }\end{array}$ & $\begin{array}{l}\text { Impact } \\
\text { Factor }\end{array}$ & $\begin{array}{l}\text { t-Statistics } \\
\text { (bootstrap) }\end{array}$ \\
\hline H1a market dynamism & + & $0.014-$ & $0.2554^{* * *}$ \\
H2a competitive intensity & + & 0.14 & $1.8192^{* *}$ \\
H3a centralization & + & $0.002-$ & $0.03-^{-}$ \\
H4a trust culture & + & 0.179 & $1.8991^{* *}$ \\
H5a users attitude & + & 0.269 & $2.8564^{* * *}$ \\
H6a leadership behaviour & + & 0.16 & $1.695^{* *}$ \\
H7a consensus & + & 0.163 & 1.5578 \\
H8a interactive use of budget & + & 0.189 & $1.909^{* *}$ \\
Coefficient of Determination & 0.598 & & \\
\hline
\end{tabular}

Significant at $95 \%{ }^{* * *} * *$ Significant at $90 \%$

As it is shown in table 4 and by comparison of T-statistic with 1.96 and -1.96 numbers for $95 \%$ confidence level and 1.65 and -1.65 for $90 \%$ confidence level, it can be concluded that there is a significant relationship between market dynamism, trust culture, users attitude and leadership behavior and interactive use of budget; while centralization has a significant relationship with interactive use of budget at $90 \%$ confidence level, so $\mathrm{H} 1_{b}, H 3_{b}, H 4 b, H 5 b, H 6 b$ are approved. Also Coefficient of Determination is shown in the last line show that effective determinants on interactive use of budget explain $53 \%$ changes of this kind of budget use.
Table 4. Determinants of the interactive use of budget.

\begin{tabular}{llll}
\hline $\begin{array}{l}\text { Effective determinants of the } \\
\text { interactive use of budgets }\end{array}$ & $\begin{array}{l}\text { Expected } \\
\text { effect }\end{array}$ & $\begin{array}{l}\text { Impact } \\
\text { Factor }\end{array}$ & $\begin{array}{l}\text { t-Statistics } \\
\text { (bootstrap) }\end{array}$ \\
\hline H1a market dynamism & + & 0.364 & $4.4696^{* * *}$ \\
H2a competitive intensity & + & 0.022 & 0.3507 \\
H3a centralization & + & $0.173-$ & $1.8704-^{* *}$ \\
H4a trust culture & + & 0.208 & $2.0639^{* * *}$ \\
H5a users attitude & + & 0.265 & $2.5111^{* * *}$ \\
H6a leadership behaviour & + & 0.246 & $2.6868^{* * *}$ \\
H7a consensus & + & $0.037-$ & $0.6302-$ \\
Coefficient of Determination & 0.528 & & \\
\hline
\end{tabular}

Significant at $95 \%{ }^{* * *} * *$ Significant at $90 \%$

Consequences of the interactive and diagnostic use of budgets

T-statistic is presented for $\mathrm{H} 9$ (a, b), $\mathrm{H} 10$ (a, b), $\mathrm{H} 11$ (a, b) in table of $5 \& 6$.

Table 5. Consequences of diagnostic use of budgets.

\begin{tabular}{llll}
\hline $\begin{array}{l}\text { Consequences of diagnostic } \\
\text { use of budget }\end{array}$ & $\begin{array}{l}\text { Expected } \\
\text { effect }\end{array}$ & $\begin{array}{l}\text { Impact } \\
\text { factor }\end{array}$ & $\begin{array}{l}\text { t-Statistics } \\
\text { (bootstrap) }\end{array}$ \\
\hline H9a strategy implementation & + & 0.553 & $6.5474^{* * *}$ \\
H10a strategy formulation & + & 0.581 & $7.0674^{* * *}$ \\
H11a financial performance & Undirected & 0.416 & $3.5572^{* * *}$ \\
\hline
\end{tabular}

Significant at $95 \%^{* * *}$

Table 6. Consequences of interactive use of budgets.

\begin{tabular}{llll}
\hline $\begin{array}{l}\text { Consequences of } \\
\text { interactive use of budgets }\end{array}$ & $\begin{array}{l}\text { Expected } \\
\text { effect }\end{array}$ & $\begin{array}{l}\text { Impact } \\
\text { factor }\end{array}$ & $\begin{array}{l}\text { t-Statistics } \\
\text { (bootstrap) }\end{array}$ \\
\hline H9a strategy implementation & + & 0.321 & $3.9333^{* * *}$ \\
H10a strategy formulation & + & 0.314 & $3.8392^{* * *}$ \\
H11a financial performance & undirected & $0.002-$ & $0.0251-$ \\
\hline
\end{tabular}

Significant at $95 \%{ }^{* * * * *}$ Significant at $90 \%$

It can be said that by $95 \%$ confidence, there is a positive and significant relationship between both type of budget uses and strategy formulation and implementation. In fact, despite the existence of positive relationship between diagnostic use of budget and financial performance, there is no relationship between interactive use of budget and financial performance; so $\mathrm{H} 9(\mathrm{a}, \mathrm{b}), \mathrm{H} 10(\mathrm{a}, \mathrm{b})$ and $\mathrm{H} 11_{\mathrm{a}}$ is accepted and $\mathrm{H} 11_{\mathrm{b}}$ is rejected. Coefficients of determination show that interactive and diagnostic use of budget explains respectively $65 \%$ and $61 \%$ changes in strategy formulation and implementation and diagnostic use of budget explains just $17 \%$ changes in financial performance; because so many factors affect financial performance.

Table 7. Coefficient of determination of consequences of the interactive and diagnostic use of budgets.

\begin{tabular}{ll}
\hline Consequences & Coefficient of determination \\
\hline strategy implementation & 0.646 \\
strategy formulation & 0.612 \\
financial performance & 0.172 \\
\hline
\end{tabular}

The results can be shown in following model: 


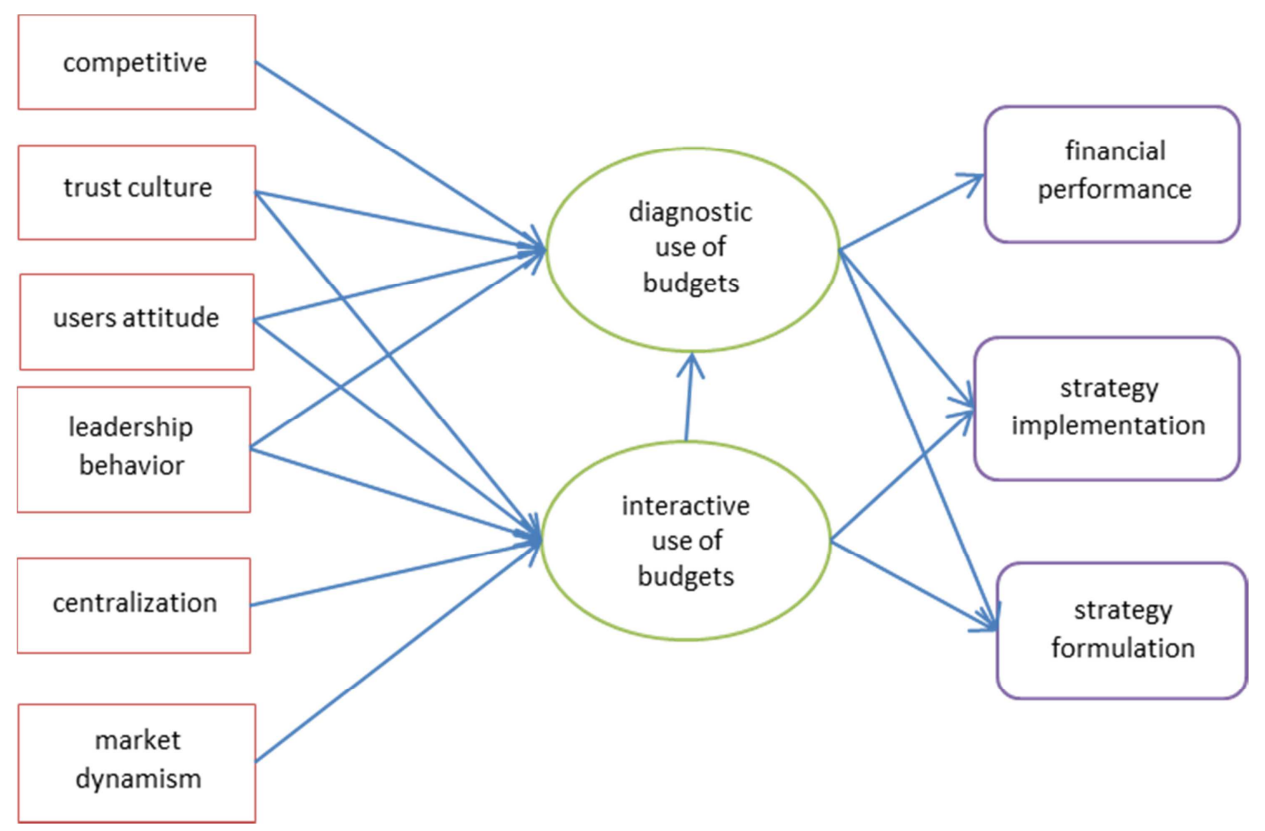

Figure 4. The conceptual model of the results.

\section{Discussion and Conclusion}

By analysis of boot strap test, the factors effecting on diagnostic use of budget include: leadership behavior, users attitudes, competition intensity, and interactive use of budget. Furthermore the factors effecting interactive use of budget include: market dynamism, centralization, trust culture, users attitudes and leadership behavior. The results of research showed that both type of budget uses is effective on strategy formulation and implementation and just diagnostic use of budget has positive effect on financial performance. In next section, we analysis the results and comprise with previous research.

\subsection{Environmental Factors}

According to results, market dynamism has a positive effect on interactive use of budget and competition intensity has a positive effect on diagnostic use of budget between environmental factors. This result is inconsistent with the outcome of Hofmann, et al. (2012) research (negative relationship between market dynamism and interactive use of budget and positive relationship between competitive intense and interactive use of budget). Hofmann, et al. (2012) by reference to Vandenbosch and Huff (1997) research explain that in cases of low and high uncertainty, managers prefer to focus on information (diagnostic use of budget) instead of time-consuming information scanning (interactive use of budget). This is despite the fact that the results of this study show when the market dynamics /competitive intensity is higher, interactive/diagnostic use of the budget will increase. In other words, depending on the type of environmental uncertainty (further market dynamics or competitive intensity), managers prefer one of the budget.

\subsection{Organizational Factors}

The same as Hofmann, et al. (2012) we concluded that there is a negative relationship between centralization and interactive use of budget and there is a positive relationship between trust culture and diagnostic use of budget. But despite the existence of a positive relationship between trust culture and interactive use of budget in Hofmann, et al. (2012), we didn't find such a relationship in the present study. Hofmann, et al. (2012) emphasis that interactive use of budget is more common in decentralized environments because interactive use of budget is more capable to overcome the problems of moral hazard in this situation. Also they believe that positive relationship between trust culture and diagnostic use of budget is justifiable because trust culture acts as a driving for management by exception and diagnostic control approach.

\subsection{Individual Factors}

Positive relationship between user's attitude and both types of budget and positive relationship between leadership behaviors with interactive use of budget is compatible with Hofmann, et al. (2012) research. Despite the lack of communication between the leadership behavior and diagnostic use of budget in Hoffman, et al. (2012) research, the results of current research show positive relationship between them. Also despite of positive relationship between consensus and diagnostic use of budget in their research, we don't find such relationship. According to the study of Hoffman, et al. it can be said that the positive relationship between user's attitude and both type of budget uses have empirical support. Also, research has shown that if the leadership behaviors among members of the organization increase the diagnostic use of budget will increase. 


\subsection{The Relationship Between Diagnostic and Interactive Use of Budget}

According to research of Hoffman, et al. (2012), we concluded that interactive and diagnostic use of budget relates to each other, and the first one has a positive and significant impact on the latter. Hoffman, et al. (2012) point out that these results are consistent by Vidner (2007) assumption that the information produced by interactive control systems support strategies and the objectives of diagnostic control system.

\subsection{The Consequences of Diagnostic and Interactive Use of Budget}

The positive relationship between interactive and diagnostic use of budget and strategy formulation\& implementation is consistent with Hoffman, et al. (2012) research. Despite the extensive research about the positive effects of management control system on strategy formulation and implementation, Simon (1990) show that not only control systems are important for strategy formulation, but also they are important for strategy implementation. This study suggests that diagnostic and interactive use of budget explains on average $60 \%$ changes strategy formulation and implementation. These results can add knowledge about the effects of information control systems on strategy formulation and implementation.

On the other hand, positive and significant relationship between diagnostic use of budget and financial performance is consistent with Hoffman, et al. (2012) study while in spite of negative relationship between interactive use of budget and financial performance in their research, we don't find such results. By reference to Hoffman, et al. (2012) research, positive effects of diagnostic use of budget on financial performance can be justified; this kind of budget use helps efficient and effective achievement of organizational goals, Help to find deviations and where necessary, apply corrective measures stems.

\section{Limitations and Further Research}

Although the present study provide a basis for identifying the effective factors on the use of budget and the outcomes of it, but, it is certainly faced with numerous restrictions because of new and innovative subject and rare volume of foreign and domestic researches such as limitations of the methodology and empirical basis. It is suggested that these issues must be considered in future researches.

Major and important limitations conclude:

1. Lack of generally accepted standards for measuring diagnostic and interactive use of budget and applying concepts and variables;

2. Reviewing the staff views in financial section in lots of companies of a vast variety of industries. So their answers may be individual opinion instead of what is happening in their companies exactly.
Also it is suggested that in addition to budget as an important part of the management control systems, other items such as performance measurement systems must be examined. In addition, in future research we can consider the prevalence of each of the budget use among different industries.

\section{References}

[1] Armesh, H., Salarzehi, H., Kord, B. (2010). Management Accounting System, Interdisciplinary Journal of Contemporary Research in Business, 2 (6), 193-206.

[2] Chong, K. M., Mahama, H. (2013). The Impact of Interactive and Diagnostic Uses of Budgets on Team effectiveness, Management Accounting Research. 25 (3), 206-222.

[3] Hofmann, S., Wald, A., Gleich, R. (2012). Determinants and Effects of the Diagnostic and Interactive Use of Control Systems: an Empirical Analysis on the Use of Budgets, Journal of Management Control, 23 (3), 153-182.

[4] Simon, R., (1990). The Role of Management Control Systems in Creating Competitive Advantage: New Perspective, Accounting Organizations and Society, 5 (1/2), 127-143.

[5] Theriou, N., D. Maditinos and. Z. Sevic. (2009).Management Control Systems and Strategy: A Resource based Perspective. Evidence from Greece, 7th International Conference on Accounting and Finance in transition - ICAFT, 23-25 July 2009, Greenwich University, London, UK.

[6] Abernethy, M. A., Bouwens, J., \& Van Lent, L. (2010). Leadership and control system design. Management Accounting Research, 21, 2-16.

[7] Bisbe, J., \& Malagueño, R. (2009). The choice of interactive control systems under different innovation management modes. European Accounting Review, 18, 371-405.

[8] Mundy, J. (2010). Creating dynamic tensions through a balanced use of management control systems. Accounting, Organizations and Society, 35, 499-523.

[9] Antonakis, J., Bendham, S., Jacquart, P., \& Lalive, R. (2010). On making causal claims: a review and recommendations. The Leadership Quarterly, 21, 1086-1120.

[10] Bhimani, A., \& Langfield-Smith, K. (2007). Structure, formality and the importance of financial and non-financial information in strategy development and implementation. Management Accounting Research, 18, 3-31.

[11] Bisbe, J., \& Otley, D. T. (2004). The effects of the interactive use of management control systems on product innovation. Accounting, Organizations and Society, 29, 709-737.

[12] Cadez, S., \& Guilding, C. (2008). An exploratory investigation of an integrated contingency model of strategic management accounting. Accounting, Organizations and Society, 33, 836-863.

[13] Naranjo-Gil, D, \& Hartmann, F. (2006). How top management teams use management accounting systems to implement strategy. Journal of Management Accounting Research, 18, $21-53$. 